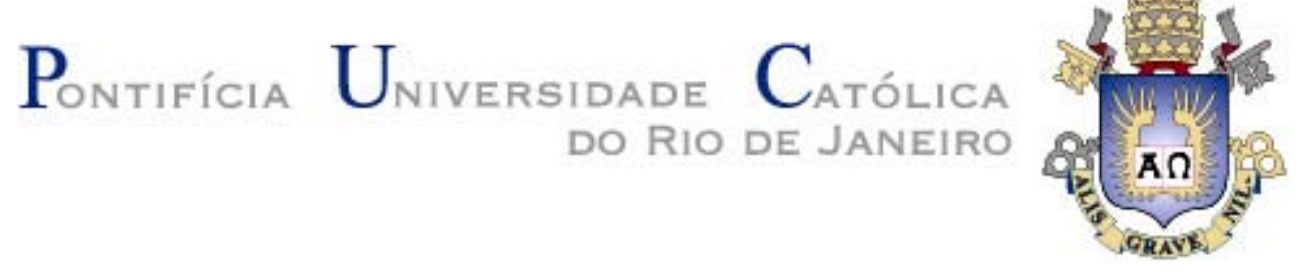

Rosana Silvina Codaro

\title{
Âncoras de Carreira e Satisfação no Trabalho
}

Dissertação de Mestrado

Dissertação apresentada ao Programa de Pósgraduação em Administração de Empresas da PUCRio como requisito parcial para obtenção do título de Mestre em Administração de Empresas

Orientadora: Profa. Patrícia Amélia Tomei

Rio de Janeiro, fevereiro de 2015. 


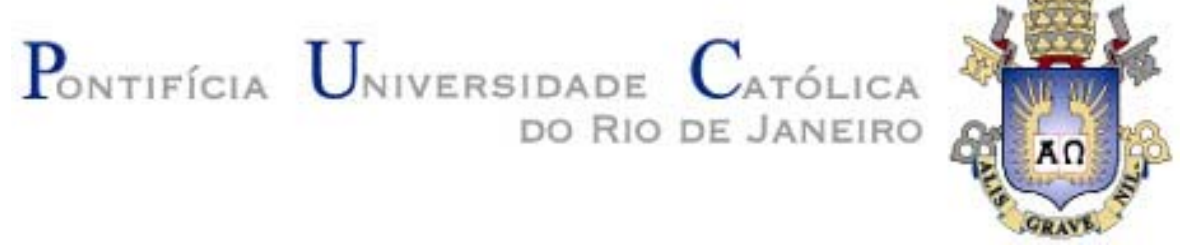

Rosana Silvina Codaro

\title{
Âncoras de Carreira e Satisfação no Trabalho
}

Dissertação apresentada como requisito parcial para obtenção do grau de Mestre pelo Programa de PósGraduação em Administração de Empresas da PUC-Rio. Aprovada pela Comissão Examinadora abaixo assinada.

\author{
Profa. Patricia Amelia Tomei \\ Orientadora \\ Departamento de Administração - PUC-Rio
}

Profa. Ana Heloísa da Costa Lemos Departamento de Administração - PUC-Rio

Prof. Giuseppe Maria Russo

Dedix Assessoria Técnico-Científica Ltda.

Profa. Mônica Herz Vice-Decana de Pós-Graduação do CCS - PUC-Rio Rio de Janeiro, 27 de fevereiro de 2015 
Todos os direitos reservados. É proibida a reprodução total ou parcial do trabalho sem autorização da universidade, da autora e da orientadora.

\section{Rosana Silvina Codaro}

Licenciada em Análise de Sistema pela Faculdade de Engenharia, Universidade de Buenos Aires. Cursou MBA Management na Escola de Administração da PUC-Rio.

Ficha Catalográfica

Codaro, Rosana Silvina

Âncoras de carreira e satisfação no trabalho / Rosana Silvina Codaro ; orientadora: Patrícia Amélia Tomei. - 2015.

100 f. : il. (color.) ; $30 \mathrm{~cm}$

Dissertação (mestrado)-Pontifícia Universidade Católica do Rio de Janeiro, Departamento de Administração, 2015.

Inclui bibliografia

1. Administração - Teses. 2. Carreira. 3. Âncora de carreira. 4. Satisfação no trabalho. I. Tomei, Patrícia Amélia. II. Pontifícia Universidade Católica do Rio de Janeiro. Departamento de Administração. III. Título.

CDD: 658 


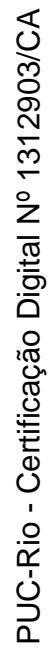

Aos meus pais 


\section{Agradecimentos}

Agradeço a Professora Patrícia Amélia Tomei pelo tempo e paciência dedicados para nossas conversas nos últimos meses que, ainda que "ancoradas" na presente dissertação, estenderam-se para incluir trocas enriquecedoras sobre profissão, carreira, futuro e, acima de tudo, sobre valores. 


\section{Resumo}

Codaro, Rosana Silvina; Tomei, Patricia Amelia. Âncoras de Carreira e Satisfação no Trabalho. Rio de Janeiro, 2015. 100p. Dissertação de Mestrado - Departamento de Administração, Pontifícia Universidade Católica do Rio de Janeiro.

O presente estudo visa analisar a relação entre satisfação no trabalho e o alinhamento do emprego do indivíduo com suas habilidades, necessidade e valores, denominadas âncoras de carreira. Para tanto, foi realizada uma pesquisa quantitativa, um survey baseado no Modelo de Âncoras de Carreira de Schein e Van Maanen (2013) e na Escala de Satisfação do trabalho de Siqueira (2008), para uma amostra não probabilística de 96 alunos de uma escola de Administração de uma universidade privada de Rio de Janeiro. A partir da pesquisa concluímos que não existe associação significativa entre a satisfação no trabalho e o alinhamento com a âncora de carreira. A âncora que apresentou maior frequência, independente do gênero do entrevistado, foi Estilo de Vida, indicando a tendência de se buscar uma carreira que permita equilibrar a vida profissional e a vida pessoal. Por outro lado, foi observado que participantes do sexo masculino priorizam mais a âncora Autonomia e os de sexo feminino a de Competência Técnica / Funcional. Por fim, também identificamos na pesquisa que os indivíduos autônomos são mais satisfeitos que os assalariados, os de sexo masculino estão mais satisfeitos no trabalho do que os de sexo feminino e que existe uma associação positiva entre anos de experiência e satisfação no trabalho.

\section{Palavras-chave}

Carreira; âncora de carreira; satisfação no trabalho. 


\section{Abstract}

Codaro, Rosana Silvina; Tomei, Patricia Amelia (Advisor). Career Anchors and Job Satisfaction. Rio de Janeiro, 2015. 100p. MSc. Dissertation - Departamento de Administração, Pontifícia Universidade Católica do Rio de Janeiro

The present study explores the relationship between job satisfaction and congruence between the individual's actual occupation and his talents, needs and values, namely his “career anchors”. For that purpose, a quantitative survey using Schein e Van Maanen's Career Anchor model (2013) and Siqueira's Job Satisfaction survey (2008) was performed for a non-probabilistic sample of 96 undergraduate and graduate students at the Business School of a private University in Rio de Janeiro. The results of that survey showed that there is no significant association between satisfaction at work and congruence with career anchor. The most frequent career anchor for both genders was Lifestyle, showing a trend towards a career that allows some balance between professional and personal life. Male participants prioritize more Autonomy and Independence, females prioritize more Technical and Functional Competence. The study showed also that self employed individuals are more satisfied than the ones employed, that among the employed individuals, men are more satisfied at work than women and that there is a significant association between years of experience and work satisfaction.

\section{Keywords}

Careers; career anchors; job satisfaction 


\section{Sumário}

1. Introdução 13

1.1. Contexto Situação Problema 13

1.2. Objetivos do Estudo 16

1.3. Relevância do Estudo 17

1.4. Delimitação do Estudo 17

1.5. Estrutura da Dissertação 18

2. Referencial Teórico 19

2.1. Conceito de Carreira 19

2.2. Modelo de E. Schein e Van Maanen de Âncoras de Carreira 26

2.2.1. Competência Técnico - Funcional (TEC) 31

2.2.2. Competência Gerencial (GER) 32

2.2.3. Autonomia e Independência (AUT) 34

2.2.4. Segurança e Estabilidade (SEG) 35

2.2.5. Criatividade Empreendedora (CRI) 36

2.2.6. Senso de Serviço / Dedicação a uma Causa (SER) 37

2.2.7. Desafio Puro (DES) 38

2.2.8. Estilo de Vida (EST) 38

2.3. Questionamentos e Criticas às Âncoras de Carreira Segundo a Literatura Organizacional 40

2.4. Estudos Nacionais Utilizando o Modelo de Âncoras de Carreira

2.5. Satisfação no Trabalho

43

45

3. Metodologia $\quad 52$

3.1. Tipo de Pesquisa $\quad 52$

3.2. Universo e Amostra da Pesquisa 52

3.3. Coleta de Dados 53

3.3.1. Questões Referentes ao Perfil do Entrevistado 53

3.3.2. Questões Sobre as Características do Trabalho Atual 53

3.3.3. Escala de Âncoras de Carreira: Schein e Van Maanen (2013) 54

3.3.4. Escala Satisfação no Trabalho: Siqueira (2008) 54

3.4. Modelo Conceitual da Pesquisa e Segmentação da Amostra 55

3.5. Questões e Ferramentas de Análise 56

3.5.1. Hipóteses da Pesquisa 56

3.5.2. Estatística Descritiva e Testes de Associação 57

3.6. Limitações do Método 58

3.6.1. Limitações Relacionadas à Escolha dos Participantes da
Pesquisa

3.6.2. Limitações Decorrentes do Método Empregado para a
Coleta de Dados 
4. Análise dos Resultados 60

4.1. Características da Amostra 60

4.2. Análises de Resultados 63

4.2.1. Escolha de Carreiras e Âncoras 63

4.2.2. Perfil da Amostra - Âncoras de Carreira 65

4.2.3. Perfil da Amostra - Satisfação no Trabalho 70

4.2.4. Perfil da Amostra - Associação entre Alinhamento e

Satisfação $\quad 71$

4.2.4.1. Indivíduos Alinhados e não Satisfeitos $\quad 75$

4.2.4.2. Indivíduos Não Alinhados e Satisfeitos 77

4.2.5. Análise de Associação das Características dos Indivíduos
Entrevistados com Satisfação e com Alinhamento

5. Conclusões e Recomendações 86

6. Referências Bibliográficas 90

Anexo 95 


\section{Lista de tabelas}

Tabela 1 - Frequência absoluta e relativa das características da Amostra

Tabela 2 - Frequência absoluta e relativa das âncoras

Tabela 3 - Frequência absoluta e percentual coluna das âncoras vs tipo de emprego

Tabela 4 - Frequência absoluta e percentual linha das âncoras vs tipo de empresa - somente empregados

Tabela 5 - Frequência absoluta e percentual linha das âncoras vs sexo

Tabela 6 - Frequência absoluta e relativa da classificação da Satisfação

Tabela 7 - Média, mediana e desvio padrão da satisfação

Tabela 8 - Frequência absoluta e relativa do alinhamento

Tabela 9 - Alinhamento vs Classificação da satisfação e p-valor Do teste de qui-quadrado para independência

Tabela 10 - Frequência absoluta, percentual linha e coluna e p-valor do teste de qui-quadrado para independência das variáveis descritivas vs alinhamento - indivíduos alinhados e não satisfeitos

Tabela 11 - Frequência absoluta, percentual linha e coluna, p-valor do teste de qui-quadrado para independência das variáveis descritivas vs alinhamento - indivíduos não alinhados e satisfeitos

Tabela 12 - Média, mediana e desvio padrão e p-valor da pontuação de satisfação vs variáveis, descritivas e alinhamento Tabela 13 - Frequência absoluta, percentual linha e p-valor do Teste de qui-quadrado para independência das variáveis descritivas e alinhamento vs classificação da satisfação Tabela 14 - Frequência absoluta, percentual coluna e p-valor do Teste de qui-quadrado para independência das variáveis descritivas vs alinhamento 


\section{Lista de gráficos}

Gráfico 1 - Participantes por idade (\%) 61

Gráfico 2 - Participantes por gênero (\%) 62

Gráfico 3 - Participantes por anos de experiência (\%) 62

Gráfico 4 - Participantes por tipo de emprego/empresa (\%) 62

Gráfico 5 - Ranking Âncoras de Carreira - total da amostra (\%) 66

Gráfico 6 - Ranking de Âncoras de Carreira por tipo de emprego /

Empresa (\%)

67

Gráfico 7 - Ranking de Âncoras de Carreira por gênero (\%)

69 


\section{Lista de figuras}

Figura 1 - Modelo revisado de Âncora de Carreira 41

Figura 2 - Teoria da característica do trabalho 49

Figura 3 - Esquema conceitual da Metodologia 55

Figura 4 - Subgrupos para análise $\quad 56$

Figura 5 - Representação das relações estudadas 56

Figura 6 - Representação das relações estudadas 63

Figura 7 - Composição dos subgrupos estudados $\quad 74$

Figura 8 - Subgrupos que "rejeitam a hipótese primária" 80 